DOI 10. 18307/2017. 0319

(C) 2017 by Journal of Lake Sciences

\title{
蓄水初期三峡水库草堂河水一气界面 $\mathrm{CO}_{2}$ 和 $\mathrm{CH}_{4}$ 通量日变化特征及 其影响因素
}

\author{
汪国骏 ${ }^{1}$, 胡明明 $2,3 * *$, 王雨春 ${ }^{2,3 * *}$, 袁 浩 $^{4}$, 蒋 蓉 $^{4}$, 王启文 ${ }^{2,3}$, 叶振亚 ${ }^{1}$, 梁顺田 ${ }^{2}$ \\ ( 1 :三峡大学水利与环境学院,宜昌 443002 ) \\ (2: 中国水利水电科学研究院, 北京 100038) \\ (3: 流域水循环模拟与调控国家重点实验室, 北京 100038) \\ (4:水利部水文局,北京 100053 )
}

\begin{abstract}
摘 要: 为查明三峡水库蓄水初期典型支流水一气界面 $\mathrm{CO}_{2}$ 和 $\mathrm{CH}_{4}$ 通量的日变化特征, 采用 LGR 在线分析仪-通量箱法, 于 2015 年 9 月初在库腹一级支流草堂河回水区开展连续 $24 \mathrm{~h}$ 的定位观测. 结果表明, $24 \mathrm{~h}$ 监测期内, 支流库湾水一气界 面 $\mathrm{CO}_{2}$ 通量变幅为 $-81.642 \sim 180.991 \mathrm{mg} /\left(\mathrm{m}^{2} \cdot \mathrm{h}\right)$, 呈“昼吸夜放”特征, 均值为 $17.346 \mathrm{mg} /\left(\mathrm{m}^{2} \cdot \mathrm{h}\right)$, 总体为释放特征; $\mathrm{CH}_{4}$ 全天均表现为释放状态, 释放通量均值为 $0.064 \mathrm{mg} /\left(\mathrm{m}^{2} \cdot \mathrm{h}\right)$, 呈 “昼弱夜强” 变化. 相关分析结果表明, $\mathrm{CH}_{4}$ 和 $\mathrm{CO}_{2}$ 释 放通量与风速呈正相关, 与表层水温、溶解氧浓度、叶绿素 a 浓度呈负相关, 说明风速物理扰动、浮游植物光合作用是控制 草堂河水一气界面气体通量最重要的环境因素. 同时, 干-支流相互作用形成的特殊水环境 (如异重流、水温分层) 也与 水一气界面温室气体通量过程密切相关,但是其作用机制更为复杂,应开展进一步系统观测和深人研究.

关键词: 三峡水库;草堂河;水一气界面;温室气体通量;连续原位观测;环境因素

\section{Diurnal variation and influencing factors of carbon dioxide and methane emissions at wa- ter-air interface of Caotang River, Three Gorges Reservoir in the initial impoundment pe- riod}

WANG Guojun ${ }^{1}$, HU Mingming ${ }^{2,3 * *}$, WANG Yuchun ${ }^{2,3 * *}$, YUAN $\mathrm{Hao}^{4}$, JIANG Rong ${ }^{4}$, WANG Qiwen ${ }^{2,3}$, YE Zhenya ${ }^{1} \&$ LIANG Shuntian ${ }^{2}$

(1: College of Hydraulic and Environment Engineering, Three Gorges University, Yichang 443002, P.R.China)

(2: China Institute of Water Resources and Hydropower Research, Beijing 100038, P.R.China)

(3: State Key Laboratory of Water Cycle Modeling and Controlling, Beijing 100038, P.R.China)

(4: Bureau of Hydrology, Ministry of Water Resources, Beijing 100053, P.R. China)

Abstract: With the LGR-floating chamber method, a 24-hour continuous monitoring was carried out in the initial impoundment period of Three Gorges Reservoir, in order to understand the greenhouse gases fluxes (carbon dioxide and methane) across the water-air interface of Caotang River which is the primary tributary of the reservoir. The results indicated that the fluxes of carbon dioxide and methane across the water-air interface appeared an obvious characteristic of diurnal variation. The fluxes of carbon dioxide ranged from -81.642 to $180.991 \mathrm{mg} /\left(\mathrm{m}^{2} \cdot \mathrm{h}\right)$, and the average fluxes of carbon dioxide were $17.346 \mathrm{mg} /\left(\mathrm{m}^{2} \cdot \mathrm{h}\right)$. As a result, the overall carbon dioxide showed “absorb by day and emit at night”. Methane was emitted all day with the average fluxes of methane $0.064 \mathrm{mg} /\left(\mathrm{m}^{2} \cdot \mathrm{h}\right)$ showed "strong at day and weak at night". The fluxes of carbon dioxide and methane had a positive correlation with wind speed while a negative correlation was observed with water temperature of surface layer, dissolve oxygen and chlorophyll-a. It could be explain the most important factors that influence emissions at water-air interface were phytoplankton photosyn-

* 国家自然科学基金项目 (51309252, 51679258)、国家水体污染控制与治理重大专项(2012ZX07104-001)、三峡水库 温室气体源汇监测与分析研究和三峡工程生态与环境监测系统重点站项目联合资助. 2016-01-10 收稿; 201606-13 收修改稿. 汪国骏(1990 ), 男,硕士研究生;E-mail: hmmkeke@163.com.

** 通信作者;E-mail: humingming@iwhr.com; wangyc@iwhr.com. 
thesis and bacterial metabolism process in the surface water. The changes in greenhouse gases emissions at water-air interface were also relevant to special environment (density current and thermal stratification) due to the interaction between main current and tributaries. The hydrodynamic factors were the key factors that affect carbon cycle and the greenhouse gases fluxes across the waterair interface in backwaters of tributaries, which would be worth researching.

Keywords: Three Gorges Reservoir; Caotang River; water-air interface; greenhouse gases flux; continuous monitoring; environmental factors

自 $1990 \mathrm{~s}$ 初 Rudd 等 ${ }^{[1]}$ 报道了南美热带雨林地区水库 $\mathrm{CH}_{4} 、 \mathrm{CO}_{2}$ 释放通量的观测数据以来, 水库温室气 体释放通量已成为当前国际学术界争论的核心问题 ${ }^{[2]}$. Fearnside 等甚至认为某些热带雨林地区水库的碳排 放当量可与同等发电量的使用化石燃料电厂的碳排放当量相当 ${ }^{\left[{ }^{[3]}\right.}$, 产生学术分歧的一个重要原因就是缺乏 高精度的观测数据. 事实上, 水库温室气体通量过程极其复杂, 具有极高的时空不确定性, 其变化涉及到流 域碳生物地球化学循环的宏观因素 ${ }^{[4]}$, 也与水库选址、淹没前清库、建设运行、气温、日照、风速、水动力、浮 游植物光合作用等因素密切相关 ${ }^{[5-7]}$. 特别是 $\mathrm{CO}_{2}$ 通量的日变化特征会表现出日内 “汇” 和 “源” 反转的显著 变化 ${ }^{[8]}$.

近年来围绕三峡水库生态环境问题, 国内一些学者在三峡水库干流以及主要支流水域开展了温室气体 通量观测, 获取了重要的基础观测数据 ${ }^{[8-11]}$. 由于三峡工程规模宏大、库区水面开阔、支流形态及环境条件多 样 ${ }^{[12]}$, 不同支流水一气界面温室气体释放特征也存在巨大差异. 在库首香溪河 ${ }^{[8-10]}$ 、库尾澎溪河 ${ }^{[11]}$ 开展的日 连续观测表明, 为准确估算和评估温室气体释放通量的总体效应, 有必要在典型观测 (如代表季节、代表水 期以及工程运行方式) 基础上开展以“昼-夜”为尺度的连续监测.

三峡库腹心区的一级支流草堂河地理位置特殊, 由于受熟门水面束窄“狭管效应” 及河口夹角的影响, 尤其在三峡水库汛末开始蓄水期间, 干流顶托、倒灌作用加强, 干支流相互作用的水流特征明显不同于其他 支流. 总体上看, 目前在三峡水库干流与支流特殊的水动力条件下, 碳循环及伴生的水一气界面 $\mathrm{CO}_{2}$ 和 $\mathrm{CH}_{4}$ 通量过程的观测和原位资料还十分有限. 因此, 本课题组于 2015 年 9 月上旬三峡工程开始蓄水调度初期, 在草堂河回水区开展蓄水水位抬升过程温室气体通量日变化的连续定位观测, 以丰富三峡库区温室气体通 量的观测数据, 促进深人了解三峡水库温室气体产生和释放机理.

\section{1 研究区域概况}

草堂河是三峡库区重要的一级支流, 干流全长 $33.3 \mathrm{~km}$, 流域面积 $394.8 \mathrm{~km}^{2}$, 平均流量 $7.51 \mathrm{~m}^{3} / \mathrm{s}$, 年径 流总量 $2.37 \times 10^{8} \mathrm{~m}^{3}$. 草堂河地理位置为三峡库区腹心的奉节县 (图 1), 地处长江三峡中睢塘峡的人口, 翟塘 峡口 (熟门) 水面束窄 “狭管效应” 使三峡工程蓄水水文抬升过程中干流对草堂河回水倒灌作用加强. 与库 区支流普遍与长江干流呈低于 $90^{\circ}$ 夹角交叉的关系不同, 草堂河与长江呈少见的 $165^{\circ}$ 顺江交叉关系, 河口白 帝城将水流分为两支,形成了草堂河回水区特殊的水流环流特征,导致水温分层、物质循环过程具有不同于 其他支流的特殊性. 根据本课题组在草堂河的前期研究 ${ }^{[13]}$ 表明, 草堂河河口断面 8 月与 9 月的流速分布类 似, 由于受蓄水影响, 9 月流速明显大于 8 月流速, 长江干流倒灌在草堂口形成的 “左进右出” 水团环流显著 加强,干流顶托对支流回水区的影响同步加强, 水温、浊度差形成从河口到回水区不同梯度的水体分层状态.

按照三峡工程优化调度规程,三峡工程汛期实行 $145 \mathrm{~m}$ 低水位防汛运行, 8 月底开始抬升水位逐渐达到 $175 \mathrm{~m}$ 高水位运行. 如图 2 所示, 本次连续观测时段选择在三峡工程 2015 年蓄水初期, 监测时间的选择不仅 考虑了三峡水库调度运行方案, 体现出蓄水初期这一特殊时期阶段性特点; 也考虑到草堂河季节因素下水 环境特征,体现出在水库调度和季节因素下对干支流的影响特征. 在干流倒灌水流与支流滞水区交界设置 连续定点观测断面, 以查明水位变动对支流库湾水-气界面 $\mathrm{CO}_{2}$ 和 $\mathrm{CH}_{4}$ 通量动态变化的影响, 为全面准确估 算三峡水库温室气体总释放量提供重要数据支撑.

\section{2 材料与方法}

\section{1 监测方法}

本次连续监测时间为 2015 年 9 月 7 日 $12: 00$ 至 9 月 8 日 $11: 00$, 采样间隔为 $1 \mathrm{~h} . \mathrm{CO}_{2}$ 和 $\mathrm{CH}_{4}$ 水-气界面 


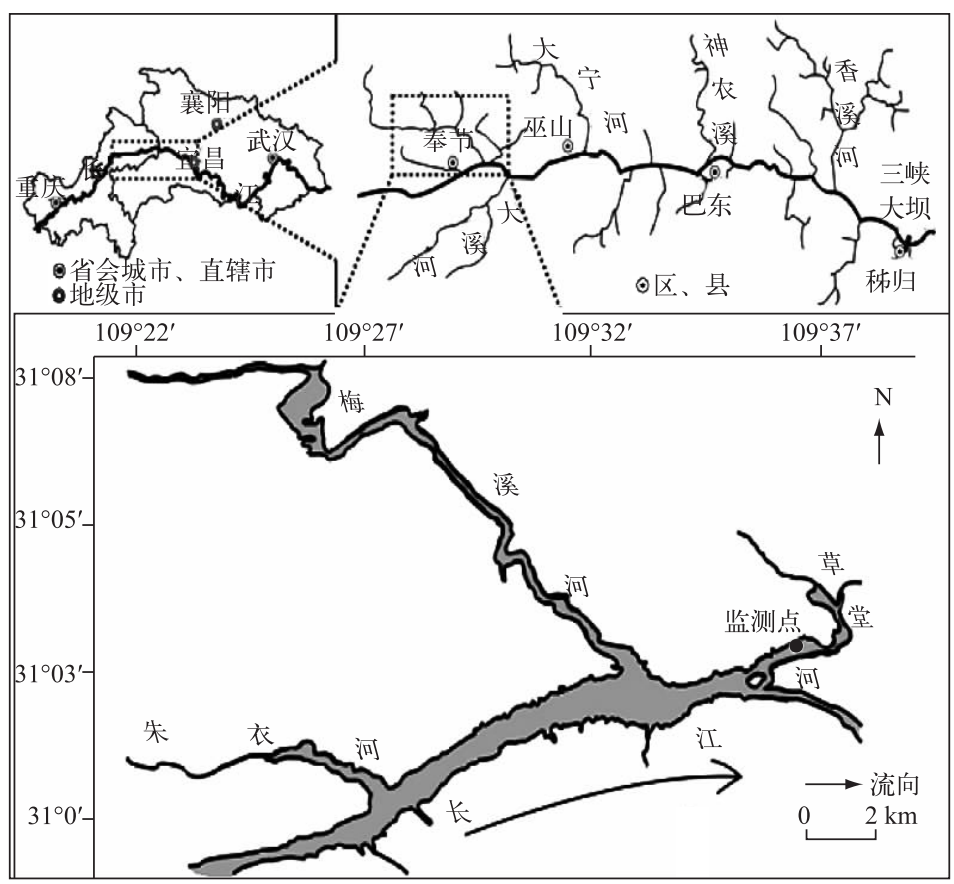

图 1 三峡水库草堂河监测点分布

Fig.1 Distribution of the sampling site of Caotang River, Three Gorges Reservoir

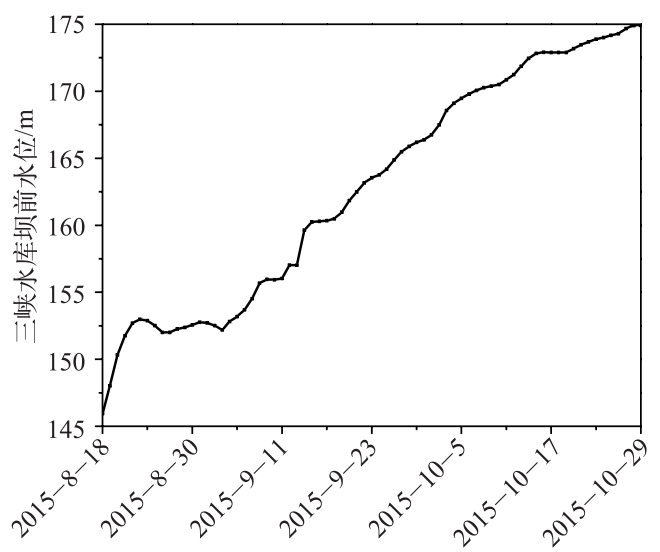

图 2 三峡水库蓄水期间水位日变化

Fig.2 Diurnal variation of water level in the impoundment period of Three Gorges Reservoir
交换通量采用 LGR-UPGA（Ultra-Portable Gas Analyzer) 型快速分析仪 (精度: 测量频率为 $1 \mathrm{~Hz}$, 精 度为 $0.001 \mathrm{ppm}$, 小于读数的 $1 \%$ ) 进行监测, 这款仪 器在 LGR- $100^{[8]}$ 型基础上, 具有体积小、方便携带的 特点, 且配有充电电池, 避免了现场供电不足的困难. 采用气体采集设备为通量箱, 箱体 (直径 $30 \mathrm{~cm}$, 高 50 $\mathrm{cm}$ ) 采用不锈钢材质. 箱体内顶部装有小型风扇, 便 于箱体内气体混合均匀, 顶部两个硅导管连接温室 气体分析仪的进出口, 避免采样过程中通量箱内气 体受外界影响, 同时对箱体做了不透光和散热处理, 通过箱体收集水一气界面以扩散方式交换的 $\mathrm{CO}_{2}$ 和 $\mathrm{CH}_{4}$ 气体. 采样前, 将箱体与空气充分混合 $3 \sim 5 \mathrm{~min}$; 采样时, 将箱体置于水面上, 保证与外界隔绝, 在水 面静置 5 10 min, 通过气体变化率计算出 $\mathrm{CO}_{2}$ 和 $\mathrm{CH}_{4}$ 气体交换通量.

现场观测期间, 使用 Kestrel 4500 风速气象仪 (NK 公司, 美国) 测定瞬时气压、温度、风速和相对湿

度, 使用 YSI-EXO2 多参数水质分析仪 (YSI 公司, 美国) 测定垂向自表层至底层每米处水温(WT)、电导率、 $\mathrm{pH}$ 、溶解氧 (DO)、叶绿素 $\mathrm{a}(\mathrm{Chl} . \mathrm{a})$ 等理化参数, 监测间隔为 $1 \mathrm{~h}$. 同时采集 $1.5 \mathrm{~L}$ 水样用于测定藻细胞密度和 常规水化学分析. 用于测定藻细胞密度的样品需加鲁哥试剂固定, 带回实验室后, 进一步沉降浓缩, 在光学 显微镜下进行计数.按《中国常见淡水浮游藻类图谱》 ${ }^{[14]}$ 对浮游植物开展鉴定工作. 


\section{2 水一气界面通量计算方法}

水一气界面 $\mathrm{CO}_{2}$ 和 $\mathrm{CH}_{4}$ 通量是指单位时间内通过垂直于扩散方向的单位截面积的扩散物质流量, 与该截 面的浓度梯度呈正比,正值表示水体向大气释放该气体,负值表示水体从大气吸收该气体. 气体通量通过箱 内气体浓度变化的斜率曲线计算,监测期间水-气界面 $\mathrm{CO}_{2}$ 和 $\mathrm{CH}_{4}$ 平均回归系数 $R^{2}$ 分别达到 0.90 和 0.93 , 计算公式为 ${ }^{[15]}$ :

$$
F=\frac{F_{1} \cdot F_{2} \cdot V}{A} \cdot \frac{\mathrm{d} c}{\mathrm{~d} t}
$$

式中, $F$ 为气体交换通量 $\left(\mathrm{mg} /\left(\mathrm{m}^{2} \cdot \mathrm{h}\right)\right) ; V$ 为通量箱水面以上体积 $\left(\mathrm{m}^{3}\right) ; \mathrm{d} c / \mathrm{d} t$ 为通量箱内气体浓度随时间 的变化率 $(\mathrm{ppm} / \mathrm{s}), c$ 为气体体积浓度 $(\mathrm{ppm})\left(1 \mathrm{ppm}=1 \mathrm{~cm}^{3} / 1 \mathrm{~m}^{3}=10^{-6}\right) ; A$ 为采样箱横截面积 $\left(\mathrm{m}^{2}\right) ; F_{1}$ 为标准 温度和压力下空气中气体浓度单位 $\mathrm{ppm}$ 与 $\mathrm{mg} / \mathrm{m}^{3}$ 的转换系数, 由理想气体状态方程得出: $P \cdot V=n \cdot R \cdot T, n=$ $m / M, m=\rho \cdot V$, 得出 $\rho=M \cdot P /(R \cdot T)$, 故 ${ }^{[15]}$ :

$$
F=\frac{M \cdot P}{R(273.13+T)} \cdot \frac{F_{2} \cdot V}{A} \cdot \frac{\mathrm{d} c}{\mathrm{~d} t}
$$

式中, $M$ 表示摩尔质量 $(\mathrm{g} / \mathrm{mol}) ; R$ 为理想气体常数 $(\mathrm{J} /(\mathrm{K} \cdot \mathrm{mol})) ; P$ 为各个时间点采样时箱内平均温度气 压 $(\mathrm{Pa}) ; T$ 为各个时间点采样时箱内平均温度 $\left({ }^{\circ} \mathrm{C}\right) ; F_{2}$ 为时间秒与小时的单位转换系数 (3600).

\section{3 结果与分析}

\section{1 草堂河水一气界面 $\mathrm{CO}_{2}$ 和 $\mathrm{CH}_{4}$ 通量特征}

三峡水库草堂河水一气界面 $\mathrm{CO}_{2}$ 和 $\mathrm{CH}_{4}$ 交换通量均具有明显的日变化特征(图 3).

$\mathrm{CO}_{2}$ 释放通量变化范围为 $-81.642 \sim 180.991 \mathrm{mg} /\left(\mathrm{m}^{2} \cdot \mathrm{h}\right), \mathrm{CO}_{2}$ 从 12:00 到 21:00 表现为吸收状态, 为 “碳汇”; 夜间从 22:00 到次日 9:00 表现为释放状态, 为“碳源”, 从 10:00 开始又出现吸收状态, 形成一个完 整的循环. 期间 16:00 达到最高峰,夜间释放明显,在凌晨 4:00 通量达到最大值.

$\mathrm{CH}_{4}$ 则在 $24 \mathrm{~h}$ 内均表现为释放状态,通量变幅在 $0.007 \sim 0.249 \mathrm{mg} /\left(\mathrm{m}^{2} \cdot \mathrm{h}\right)$ 之间. 昼夜释放通量差异较 大, 夜间的释放通量明显高于白天, 白天平均释放通量为 $0.023 \mathrm{mg} /\left(\mathrm{m}^{2} \cdot \mathrm{h}\right)$, 夜间平均释放通量达到 0.104 $\mathrm{mg} /\left(\mathrm{m}^{2} \cdot \mathrm{h}\right)$, 且在凌晨 3:00 释放通量达到最高峰.

通过观测发现, $\mathrm{CO}_{2}$ 和 $\mathrm{CH}_{4}$ 交换通量昼夜差异较大, 夜间的释放通量要显著高于白天,这可能和观测时
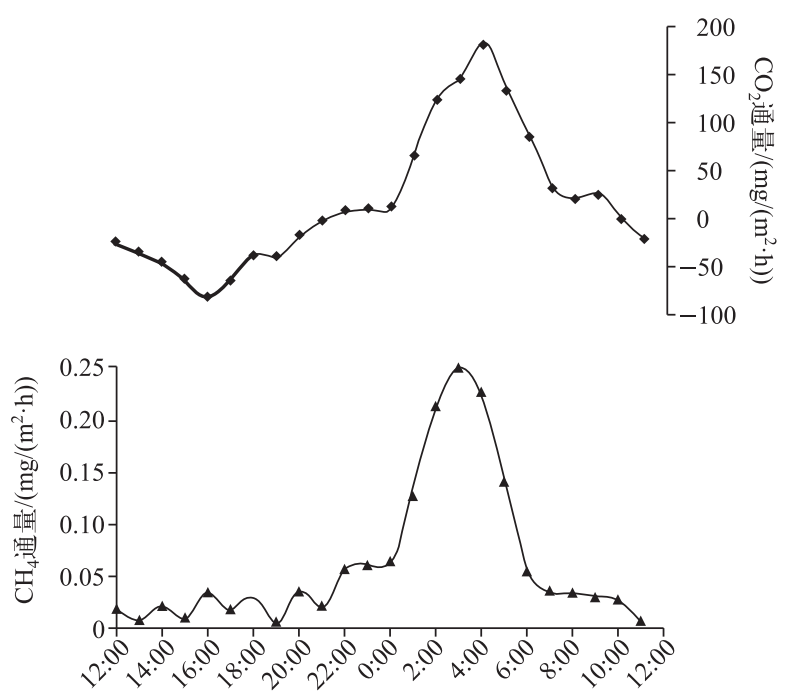

图 3 监测期间 $\mathrm{CH}_{4}$ 和 $\mathrm{CO}_{2}$ 通量的日变化

Fig.3 Diurnal variation of $\mathrm{CO}_{2}$ and $\mathrm{CH}_{4}$ fluxes during the research period 
段内夜间较大的风速及草堂河复杂的水文水动力条件等因素有关.

\section{2 环境因子变化特征}

本次 $24 \mathrm{~h}$ 温室气体通量连续观测期间, 同步观测环境因子的变化(图 4).

由于受太阳辐射影响, 大气温度白天气温较高, 在 $27.9 \sim 38.3^{\circ} \mathrm{C}$ 内波动, 平均气温达到 $33.1^{\circ} \mathrm{C}$; 夜间气温 相对于白天气温较为平稳, 在 $26.3 \sim 27.6^{\circ} \mathrm{C}$ 之间波动, 平均温度为 $26.8^{\circ} \mathrm{C}$ (图 4 ). 表层水温与大气温度同步 变化, 二者相关性显著, 相关系数达到 0.848 (表 1), 整个期间表层水温变化范围为 $25.7 \sim 28.4^{\circ} \mathrm{C}$, 观测中发现 水温存在较明显的日变化特征,白天水温分层现象要强于夜间(图 5 ).

在观测期间, 白天大气风速处于一个较低的稳定水平,基本在 $1 \mathrm{~m} / \mathrm{s}$ 以下,而集中在 1:00-4:00 这一阶 段, 风速均大于 $3 \mathrm{~m} / \mathrm{s}$ (图 4), 风速的日变化规律和 $\mathrm{CO}_{2} 、 \mathrm{CH}_{4}$ 交换通量昼夜变化规律十分相近.

表层水体 $\mathrm{pH}$ 受水体浮游植物光合作用的影响, 白天大于夜间, 15:00 达到最大值, 6:00 到达最小值, 日 变化范围为 8.68 9.13(图 4).

表层水体 DO 也与光合作用存在显著的关系, 白天平均值为 $11.66 \mathrm{mg} / \mathrm{L}$, 夜间平均值为 $9.69 \mathrm{mg} / \mathrm{L}$, 正午 $12: 00$ 达到最大值, 凌晨 4:00 到达最小值, 日变化范围为 8.78 14.12 mg/L( 图 4).

水体 Chl.a 浓度代表水生浮游植物的生物量, 影响着表层水体 $\mathrm{pH}$ 和 DO. 正午过后, 表层水体 Chl.a 发 生了垂向迁移, 故最大值出现在 16:00, 而最小值出现在凌晨 4:00, 日变化范围为 5.59 19.34 $\mu \mathrm{g} / \mathrm{L}$ (图 4).
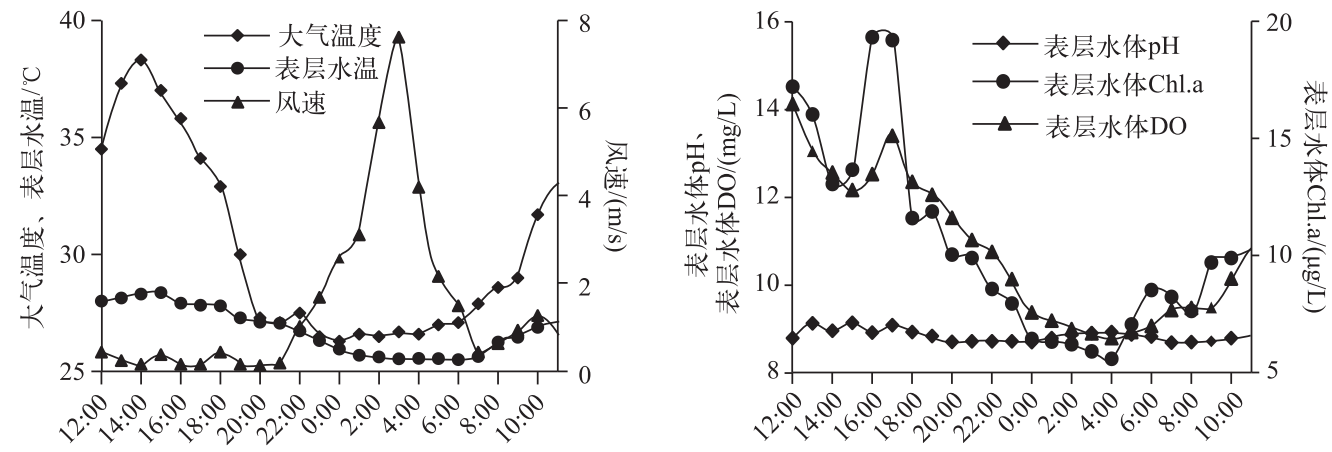

图 4 监测期间各环境因子的日变化

Fig.4 Diurnal variation of influencing factors during the research period

表 $1 \mathrm{CO}_{2}$ 和 $\mathrm{CH}_{4}$ 通量与环境因子的相关性分析

Tab.1 Correlation coefficient between influencing factors and the fluxes of $\mathrm{CO}_{2}$ and $\mathrm{CH}_{4}$

\begin{tabular}{|c|c|c|c|c|c|c|c|c|c|}
\hline & $\mathrm{CH}_{4}$ 通量 & $\mathrm{CO}_{2}$ 通量 & WT & $\mathrm{pH}$ & DO & Chl.a & 大气压力 & 大气温度 & 风速 \\
\hline $\mathrm{CH}_{4}$ 通量 & 1 & & & & & & & & \\
\hline $\mathrm{CO}_{2}$ 通量 & $0.804^{* *}$ & 1 & & & & & & & \\
\hline WT & $-0.823^{* *}$ & $-0.946^{* *}$ & 1 & & & & & & \\
\hline $\mathrm{pH}$ & -0.245 & -0.362 & $0.402^{*}$ & 1 & & & & & \\
\hline DO & $-0.816^{* *}$ & $-0.944^{* * *}$ & $0.953^{* *}$ & 0.310 & 1 & & & & \\
\hline Chl.a & $-0.844^{* *}$ & $-0.935^{* *}$ & $0.909^{* *}$ & 0.380 & $0.953^{* *}$ & 1 & & & \\
\hline 大气压力 & 0.348 & $0.661^{* * *}$ & $-0.629^{* *}$ & $0.680^{* * *}$ & $-0.629^{* * *}$ & $-0.603 * *$ & 1 & & \\
\hline 大气温度 & $-0.822^{* *}$ & $-0.801^{* *}$ & $0.848^{* * *}$ & $0.481 *$ & $0.827^{\text {*** }}$ & $0.888^{* *}$ & $-0.471^{*}$ & 1 & \\
\hline 风速 & $0.757^{* *}$ & $0.843^{\text {*** }}$ & -0.792 *** & -0.141 & $0.844^{* * *}$ & $0.856^{* *}$ & $-0.571^{*}$ & $0.734^{* *}$ & 1 \\
\hline
\end{tabular}

** 在置信度 (双测) 为 0.01 时, 相关性极显著; * 在置信度 (双测) 为 0.05 时, 相关性显著; 水体参数均使用表层水体 数据. 


\section{4 讨论}

\section{1 水温与 $\mathrm{CO}_{2}$ 和 $\mathrm{CH}_{4}$ 通量的关系}

水温作为水体最重要的理化参数, 一方面, 可以通过影响气体的交换速率和气体在水中的溶解度来直 接影响水体中溶解气体的浓度, 在相同气压下, 气体的溶解度和水温呈反比, 水温越高, 气体的溶解度越 小 ${ }^{[16]}$; 另一方面, 水温还可以通过影响微生物酶的活性来控制产生 $\mathrm{CO}_{2}$ 和 $\mathrm{CH}_{4}$ 速率 ${ }^{[17]}$ 以及通过影响水生植 物初级生产 ${ }^{[18-19]}$ 来间接影响温室气体的产生过程.

水温变化的另一个重要影响, 是可能产生温度差导致的水团混合或分层, 从而影响水体的物理稳定性, 进而破坏水体中溶解气体的热力学平衡, 加强或减弱温室气体的释放通量. 观测期间, 表层水温变化范围为 $25.7 \sim 28.4^{\circ} \mathrm{C}$, 底层水温变化范围为 $24.5 \sim 24.6^{\circ} \mathrm{C}$, 各个时间点表、底层水温差值如图 6 所示, $15: 00$ 点达到最 大值, 凌晨 3:00 到达最小值, 整个日变化范围为 $1.0 \sim 3.8^{\circ} \mathrm{C}$, 且凌晨 1:00-7:00 水温差基本处于一个稳定的 状态. 在本次研究中发现草堂河连续监测断面水温分层具有日变化特征 (图 5 ), 在已有的三峡支流水温分 层研究中出现过季节性变化 ${ }^{[20]}$, 还未见水温分层日变化的资料, 这可能与草堂河受到三峡工程蓄水水位抬 升形成的特殊倒灌环流的影响有关.

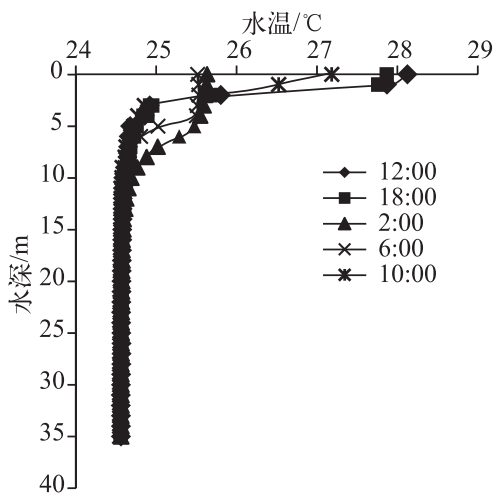

图 5 不同时刻水温分层

Fig.5 Water temperature stratification with the representative sample

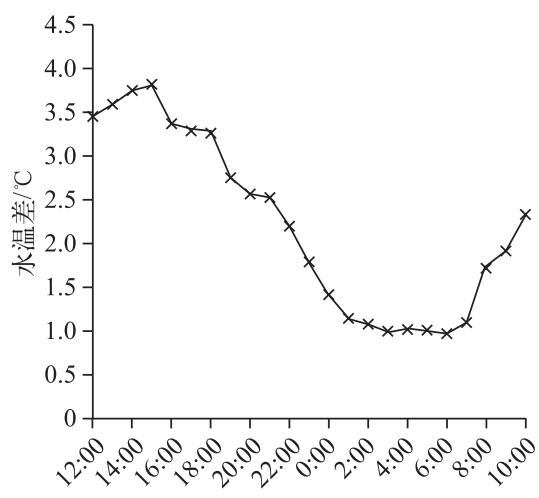

图 6 监测期间采样点表层和底层的水温差

Fig.6 Difference value of water temperature between surface layer and bottom layer during the research period

采用 Reynolds 等 ${ }^{[21]}$ 提出的 $N^{2}$ 的标准方法, 可以根据水温分层情况大致估算水体的稳定程度,进而分析 水体机械稳定对水一气界面温室气体通量的影响. 基本计算公式为:

$$
N^{2}=\frac{g}{\rho_{\text {avg }}} \cdot \frac{\mathrm{d} \rho}{\mathrm{d} z}
$$

式中, $N^{2}$ 为垂向稳定系数 $\left(\mathrm{s}^{-2}\right) ; \mathrm{d} \rho / \mathrm{d} z$ 指的是表层水体与底层水体的密度梯度, 用 $\left(\rho_{\mathrm{h}}-\rho_{0}\right) / z$ 表示, $\rho_{\mathrm{h}}$ 和 $\rho_{0}$ 分 别表示底层和表层水体密度 $\left(\mathrm{kg} / \mathrm{m}^{3}\right), z$ 表示水深 $(\mathrm{m}) ; g$ 为重力加速度 $\left(\mathrm{m} / \mathrm{s}^{2}\right) ; \rho_{\mathrm{arg}}$ 为垂向水体平均密度 $\left(\mathrm{kg} / \mathrm{m}^{3}\right)$, 一般认为 $\rho_{\text {avg }}=\left(\rho_{\mathrm{h}}+\rho_{0}\right) / 2$.

在三峡水库中, 水温和水体中含沙量是影响水体密度的主要因素, 在实测过程中, 水体含沙量较小, 此 次计算过程中忽略含沙量对水体密度的影响. 各个点水温所对应的水体密度根据《1990 年国际温标纯水密 度表》提供的数据拟合成以下公式计算而得 ${ }^{[12]}$ :

$$
\rho=10^{-11} T^{6}+5 \times 10^{-9} T^{5}-10^{-6} T^{4}+10^{-4} T^{3}-9.1 \times 10^{-3} T^{2}+6.79 \times 10^{-2} T+999.84\left(R^{2}=1.001\right)
$$

通过水温计算出水体密度进而得出不同时刻水体的垂向稳定系数 $N^{2}$. 当 $N^{2} \leqslant 5 \times 10^{-5} \mathrm{~s}^{-2}$ 时,一般认为水 体为混合水体; 当 $5 \times 10^{-4} \mathrm{~s}^{-2}>N^{2}>5 \times 10^{-5} \mathrm{~s}^{-2}$ 时,一般认为水体为弱分层水体; 当 $N^{2} \geqslant 5 \times 10^{-4} \mathrm{~s}^{-2}$ 时,一般认为 水体为分层水体 ${ }^{[20]}$.

连续监测期间, 草堂河昼夜的垂向稳定系数具有显著的波动, 最大值出现在 15:00, 垂向稳定系数为 
$2.84 \times 10^{-4} \mathrm{~s}^{-2}$; 最小值出现在凌晨 $3: 00$, 为 $0.68 \times 10^{-4} \mathrm{~s}^{-2}$. 且在凌晨 $1: 00-6: 00$ 垂向稳定系数十分接近于混 合水体到弱分层水体的判定國值 $0.5 \times 10^{-4} \mathrm{~s}^{-2}$, 此阶段水体近似于混合水体; 而对于 $12: 00-16: 00$ 而言, 垂 向稳定系数均大于 $2.5 \times 10^{-4} \mathrm{~s}^{-2}$, 在弱分层水体中处于较强的水平. 总而言之, 整个昼夜过程存在较明显水温 分层的日变化 (图 7).

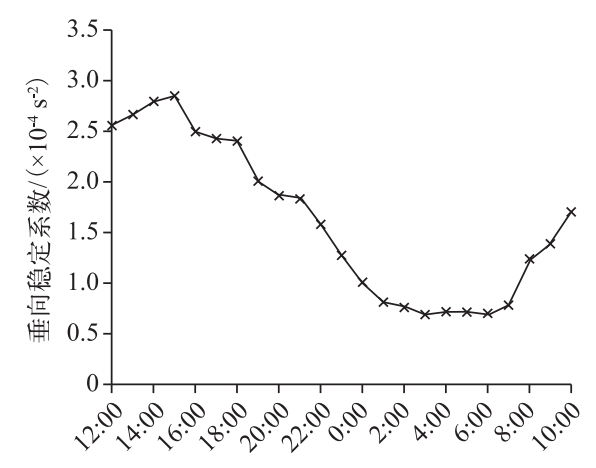

图 7 监测期间水体垂向稳定系数的日变化

Fig.7 Diurnal variation of stable coefficient of water during the research period
本次连续监测数据的相关性分析结果 (表 1 ) 表明, $\mathrm{CO}_{2} 、 \mathrm{CH}_{4}$ 通量与表层水温呈极显著负相关, 相关系数分别 为 -0.946 和 -0.823 , 因此, 对 $\mathrm{CO}_{2}$ 释放通量而言, 白天太阳 辐射强度剧烈上升, 导致表层水体迅速升温, 在白天光合作 用强烈的表层水体 $\mathrm{CO}_{2}$ 分压降低时, 开始大量吸收大气间 的 $\mathrm{CO}_{2}$, 形成 $\mathrm{CO}_{2}$ 吸收状态.

除光合作用外, $\mathrm{CO}_{2} 、 \mathrm{CH}_{4}$ 通量与由水温分层和风速扰 动导致的水体稳定性也有很大关系, 对比水体垂向稳定系 数 $N^{2}$ 变化 (图 7) 与通量过程 (图 3) 可发现, 出现水温分层 现象时, 中底部水团与表层水团交换能力减弱, 水位上升期 间淹没的有机质分解的 $\mathrm{CO}_{2}$ 无法完全通过水柱扩散至表层 水体, 但是通过物理扰动 (如风) 破坏水体稳定形成的气体 释放通量, 在本次观测中可能占有更重要的地位, 特别是对 $\mathrm{CH}_{4}$ 的释放通量变化, 风速的影响更直接. 夜晚水体充分交 换, 在较大风速的协同影响下, 加速水体 $\mathrm{CH}_{4}$ 气体的排放, 因此本次研究在此时段观测到了高通量的 $\mathrm{CH}_{4}$ 释 放 (图 3), 这在以往的研究中还未见报道, 应充分重视风速和水体稳定度对水一气界面温室气体通量估算的 影响.

与王亮等 ${ }^{[8]}$ 于 8 月和黄文敏等 ${ }^{[10]}$ 于 10 月对香溪河的观测比较发现, 本次观测结果中 $\mathrm{CO}_{2}$ 通量日变化 规律和王亮等的结果相近, $\mathrm{CH}_{4}$ 通量日变化规律与其结果相反; 而 $\mathrm{CH}_{4}$ 通量日变化规律和黄文敏等的观测有 一致的部分, 可能说明了 $\mathrm{CO}_{2} 、 \mathrm{CH}_{4}$ 通量的日变化具有高度时空异质性,有必要开展进一步观测.

\section{$4.2 \mathrm{Chl}$. a 浓度与 $\mathrm{CO}_{2}$ 和 $\mathrm{CH}_{4}$ 通量的关系}

浮游植物的生物过程是影响水体 $\mathrm{CO}_{2}$ 和 $\mathrm{CH}_{4}$ 产生与释放的重要因素, 经分析鉴定, 观测期间藻类共包含 6 门 24 属 (蓝藻门、绿藻门、硅藻门、裸藻门、隐藻门、黄藻门), 密度达到 $1.19 \times 10^{7} \mathrm{cells} / \mathrm{L}$, 其中绿藻门素衣 藻属为优势藻种, 密度达到 $5.73 \times 10^{6} \mathrm{cells} / \mathrm{L}$, 草堂河水域处于较高生产力水平. Chl. a 作为富营养化和水华 指示指标, 代表浮游植物生物量和生产力水平, 是水质监测过程中的重要指标之一.

观测期间, 表层 Chl.a 浓度昼夜间变化明显 (图 4), 白天 Chl.a 平均浓度为 $13.45 \mu \mathrm{g} / \mathrm{L}$, 夜间平均浓度为 $7.56 \mu \mathrm{g} / \mathrm{L}$. Chl. a 浓度与 $\mathrm{CO}_{2}$ 交换通量呈现极显著负相关, 相关系数为 -0.935 (表 1). 浮游植物进行光合作 用, 将无机碳转化为有机碳, 使得表层水体 $\mathrm{CO}_{2}$ 分压降低, 同时浮游生物进行呼吸作用, 消耗 DO, 释放 $\mathrm{CO}_{2}$. 白天从 11:00 到 19:00, 此时观测区域光合作用大于呼吸作用, 大气成为水体 $\mathrm{CO}_{2}$ 的重要来源, 水体吸收现 象明显. 而夜晚 Chl.a 浓度较低, 呼吸作用占优势 ${ }^{[22]}$.

表层 Chl.a 浓度与 $\mathrm{CH}_{4}$ 交换通量呈极显著负相关, 相关系数为 -0.844 (表 1). 浮游植物由于光合作用产 生大量 $\mathrm{O}_{2}$ 使得水体中溶解氧充足, 可能将沉积物中厌氧条件下产生的 $\mathrm{CH}_{4}$ 部分氧化, 造成白天 $\mathrm{CH}_{4}$ 排放量 较小; 夜间呼吸作用较强, $\mathrm{CH}_{4}$ 释放通量出现了高于白天的现象. 但是, 如前述夜间 $\mathrm{CH}_{4}$ 释放通量增加, 更可 能与风速及相关水体稳定度有关.

\section{$4.3 \mathrm{DO}$ 浓度与 $\mathrm{CO}_{2}$ 和 $\mathrm{CH}_{4}$ 通量的关系}

水体 $\mathrm{DO}$ 代表浮游植物生态过程的强度. 水体生物通过一系列活动来改变水体中 DO 浓度,一方面浮游 植物通过光合作用产生 $\mathrm{O}_{2}$, 使水体中 $\mathrm{DO}$ 浓度上升, 另一方面区域内总的呼吸作用消耗水体中 DO. 在整个 碳循环过程中, $\mathrm{CH}_{4}$ 产生于严格厌氧条件的沉积物中 ${ }^{[23]}$, 通过孔隙水进人沉积物一水界面再进人水体向上扩 散 ${ }^{[24]}$, 而在这期间, 一部分 $\mathrm{CH}_{4}$ 在沉积物的好氧层, 在有 $\mathrm{O}_{2} 、 \mathrm{NO}_{3}^{-}$和 $\mathrm{SO}_{4}^{2-}$ 为代表的氧化剂条件下, 被氧化为 $\mathrm{CO}_{2}$, 而在水体扩散期间, 水体 DO 充足, $\mathrm{CH}_{4}$ 被进一步氧化, 只有少量 $\mathrm{CH}_{4}$ 排向大气. 一般情况下, 微生物分 
解有机物消耗氧气产生 $\mathrm{CO}_{2}$, 而在表层 DO 充足的时候往往代表浮游植物光合作用强烈的时候, 此时水体 $\mathrm{CO}_{2}$ 分压降低,水体吸收 $\mathrm{CO}_{2}$.

此次监测中, 表层水体 $\mathrm{DO}$ 浓度与 $\mathrm{CO}_{2} 、 \mathrm{CH}_{4}$ 通量均呈现显著负相关, 与 $\mathrm{CO}_{2}$ 通量的相关系数为 -0.944 , 与 $\mathrm{CH}_{4}$ 通量的相关系数为 -0.816 (表 1). 监测期间 DO 浓度昼夜间变化明显. 12:00-19:00 的平均 DO 浓度 明显高于其余时间段的平均值 (图 4). 受光合作用影响显著, 白天由于浮游植物光合作用大于呼吸作用, 表 层水体 DO 充足. 对 $\mathrm{CO}_{2}$ 而言, 表层水体 $\mathrm{CO}_{2}$ 被大量消耗, 出现了吸收状态, 而对于 $\mathrm{CH}_{4}$, 大部分在扩散上升 期间被水体充足的 DO 氧化成 $\mathrm{CO}_{2}$, 使得白天 $\mathrm{CH}_{4}$ 排放微弱. 夜晚呼吸作用明显大于光合作用, 表层水体 DO 浓度明显降低, $\mathrm{CH}_{4}$ 与 $\mathrm{CO}_{2}$ 的排放明显.

\section{4 风速与 $\mathrm{CO}_{2}$ 和 $\mathrm{CH}_{4}$ 通量的关系}

水体溶解性气体在自由扩散过程中受水深、流速及风速的影响, 风速可能是影响水一气界面气体通量的 关键因素之一, 尤其是通量的日变化过程中风速对气体通量过程的影响甚大. 风速的升高使得水体表面张 力变大, 加速了整个水一气界面气体的传输速率, 风速不仅可以通过影响水一气界面交换系数影响溶解性气 体的扩散,还可以通过扰动水体加速气泡的释放.

本次连续监测期结果表明, 风速与 $\mathrm{CO}_{2} 、 \mathrm{CH}_{4}$ 通量均呈显著正相关, 与 $\mathrm{CO}_{2}$ 的相关性达到的 0.843 , 与 $\mathrm{CH}_{4}$ 的相关性达到 0.757 (表 1). 在风速大于 $3 \mathrm{~m} / \mathrm{s}$ 的情况下, $\mathrm{CO}_{2}$ 气体通量明显大于平静水面的情况 ${ }^{[25]}$. 而集中 在凌晨 $1: 00-4: 00$, 通量箱置于监测水面期间, 平均风速均大于 $3 \mathrm{~m} / \mathrm{s}$, 较大的风速加速了水体溶解性气体 的扩散,使得夜间水一气界面 $\mathrm{CO}_{2} 、 \mathrm{CH}_{4}$ 排放通量骤增.

\section{5 结论}

在三峡工程汛末蓄水过程中开展草堂河水-气界面 $\mathrm{CO}_{2}$ 和 $\mathrm{CH}_{4}$ 通量的连续观测. 结果表明, $\mathrm{CO}_{2}$ 和 $\mathrm{CH}_{4}$ 的通量昼夜交替变化显著, $\mathrm{CO}_{2}$ 通量变幅为 $-81.642 \sim 180.991 \mathrm{mg} /\left(\mathrm{m}^{2} \cdot \mathrm{h}\right), \mathrm{CH}_{4}$ 通量变幅为 $0.007 \sim 0.249$ $\mathrm{mg} /\left(\mathrm{m}^{2} \cdot \mathrm{h}\right)$. 水温、风速、Chl. a 浓度是影响水一气界面 $\mathrm{CO}_{2}$ 和 $\mathrm{CH}_{4}$ 通量的主要因素, 对 $\mathrm{CO}_{2}$ 释放通量变化而 言, 白天浮游植物光合作用可能形成强烈的 $\mathrm{CO}_{2}$ 吸收, 而与其他支流回水区不一样的是在夜间由于受到较强 的干流倒灌环流影响以及风的协同作用, 草堂河上、下层水体 $\mathrm{CO}_{2}$ 扩散作用加强, 因此本次观测 $\mathrm{CO}_{2}$ 通量夜 间显著增加; $\mathrm{CH}_{4}$ 通量与水体及沉积物中 $\mathrm{CH}_{4}$ 产生与氧化过程有关, 水体混合程度是决定其释放通量昼夜变 化的关键因素, 本次连续观测发现, 在水体垂向稳定系数 $N^{2}$ 最低的夜间, 草堂河回水区水一气界面 $\mathrm{CH}_{4}$ 通量 最大,与香溪河、澎溪河所观测的现象不一致. 草堂河 $24 \mathrm{~h}$ 连续 $\mathrm{CO}_{2}$ 和 $\mathrm{CH}_{4}$ 通量观测结果表明,受到水动力、 风速等特殊环境条件影响, $\mathrm{CO}_{2}$ 和 $\mathrm{CH}_{4}$ 通量的昼夜变化可能表现出“异常”特征, 考虑到三峡水库广大库区环 境条件的时空差异,有必要针对 $\mathrm{CO}_{2}$ 和 $\mathrm{CH}_{4}$ 通量的昼夜变化开展进一步系统观测和深人研究.

\section{6 参考文献}

[ 1 ] Rudd JWM, Harris R, Kelly CA et al. Are hydroelectric reservoirs significant sources of greenhouse gases? AMBIO, 1993, $22(4)$ : 246-248.

[ 2 ] Rosa LP, Schaeffer R. Greenhouse gas emissions from hydroelectric reservoirs. AMBIO, 1994, 23(2) : 164-165.

[ 3 ] Fearnside PM. Hydroelectric dams in the Brazilian Amazon as sources of 'greenhouse' gases. Environmental Conservation, 1995, 22(1): 7-19.

[ 4 ] Ehrlich HL. Past, present and future of biohydrometallurgy. Process Metallurgy, 1999, 9: 3-12.

[ 5 ] Matthews CJD, Joyce EM, Louis VLS et al. Carbon dioxide and methane production in small reservoirs flooding upland boreal forest. Ecosystems, 2005, 8(3): 267-285.

[ 6 ] Abril G, Guérin F, Richard S et al. Carbon dioxide and methane emissions and the carbon budget of a 10-year old tropical reservoir (Petit Saut, French Guiana). Global Biogeochemical Cycles, 2005, 19(4) : 332-336.

[ 7 ] Chen Yonggen, Li Xianghua, Hu Zhixin et al. Carbon dioxide flux on the water-air interface of the eight lakes in China in winter. Ecology and Environment, 2006, 15(4): 665-669. [ 陈永根, 李香华, 胡志新等. 中国八大湖泊冬季水-气界 面 $\mathrm{CO}_{2}$ 通量. 生态环境, 2006, 15(4): 665-669.]

[ 8 ] Wang Liang, Xiao Shangbin, Liu Defu et al. Fluxes of greenhouse gases from Xiangxi River in summer and their influen- 
cing factors. Environmental Science, 2012, 33(5): 1471-1475. [王亮, 肖尚斌, 刘德富等. 香溪河库湾夏季温室气体 通量及影响因素分析. 环境科学, 2012, 33(5): 1471-1475.]

[ 9 ] Xiao S, Wang Y, Liu D et al. Diel and seasonal variation of methane and carbon dioxide fluxes at Site Guojiaba, the Three Gorges Reservoir. Journal of Environmental Sciences, 2013, 25(10) : 2065-2071.

[10] Huang Wenmin, Zhu Kongxian, Zhao Wei et al. Diurnal changes in greenhouse gases at water-air interface of Xiangxi River in autumn and their influencing factors. Environmental Science, 2013, 34(4)：1270-1276. [黄文敏, 朱孔贤, 赵玮 等. 香溪河秋季水一气界面温室气体通量日变化观测及影响因素分析. 环境科学, 2013, 34(4) : 1270-1276.]

[11] Li Zhe, Yao Xiao, He Ping et al. Diel variations of air-water $\mathrm{CO}_{2}$ and $\mathrm{CH}_{4}$ diffusive fluxes in the Pengxi River, Three Gorges Reservoir. J Lake Sci, 2014, 26(4) : 576-584. DOI: 10.18307/2014.0412. [李哲, 姚骁, 何萍等. 三峡水库澎溪 河水一气界面 $\mathrm{CO}_{2}, \mathrm{CH}_{4}$ 扩散通量昼夜动态初探. 湖泊科学, 2014, 26(4) : 576-584.]

[12] Ji Daobin, Liu Defu, Yang Zhengjian et al. Hydrodynamic characteristics of Xiangxi Bay in Three Gorges Reservoir. Science China, 2010, (1): 101-112. [纪道斌, 刘德富, 杨正健等. 三峡水库香溪河库湾水动力特性分析. 中国科学: 物理学力学天文学, 2010, (1): 101-112.]

[13] Luo Guangfu. The influence of hydrodynamics on the exchange of nutrients in estuary of tributaries in Three Gorges Reservoir [Dissertation]. Shanghai : East China Normal University, 2014. [罗光富. 支流河口水动力作用对三峡库区干支流 营养盐交换的影响 [学位论文]. 上海: 华东师范大学, 2014.]

[14] Weng Jianzhong, Xu Hengxing eds. Chinese common freshwater planktonic algae atlas. Shanghai: Shanghai Scientific Technology Press, 2010. [翁建中, 徐恒省. 中国常见淡水浮游藻类图谱. 上海: 上海科学技术出版社, 2010. ]

[15] Goldenfum JA ed. GHG Measurement guidelines for freshwater reservoirs. London: International Hydropower Association. 2010.

[16] Wang Dongqi, Chen Zhenlou, Wang Jun et al. Fluxes of $\mathrm{CH}_{4}, \mathrm{CO}_{2}$ and $\mathrm{N}_{2} \mathrm{O}$ from Yangtze estuary intertidal flat in summer season. Geochemical, 2007, 36(1) :78-88. [王东启, 陈振楼, 王军等. 夏季长江口潮间带 $\mathrm{CH}_{4} 、 \mathrm{CO}_{2}$ 和 $\mathrm{N}_{2} \mathrm{O}$ 通量 特征. 地球化学, 2007, 36(1): 78-88.]

[17] Huttunen JT, Alm J, Liikanen A et al. Fluxes of methane, carbon dioxide and nitrous oxide in boreal lakes and potential anthropogenic effects on the aquatic greenhouse gas emissions. Chemosphere, 2003, 52(3) : 609-621.

[18] Raven JA, Geider RJ. Temperature and algal growth. New Phycologist, 1988, 110(4) : 441-461.

[19] Wu Pan, Deng Jianming, Qin Boqiang et al. Effects of enhanced water temperature and nutrient concentration on algal growth in winter and spring season in Lake Taihu, China. Research of Environmental Sciences, 2013, 26(10) : 1064-1071. [ 吴攀, 邓建明, 秦伯强等. 水温和营养盐增加对太湖冬、春季节藻类生长的影响. 环境科学研究, 2013, 26(10): 1064-1071.]

[20] Yang Zhengjian, Liu Defu, Ma Jun et al. Effects of special vertical layered water temperatures on algal bloom in Xiangxi Bay of the Three Gorges Reservoir. Engineer Journal of Wuhan University, 2012, 45(1): 1-9. [杨正健, 刘德富, 马骏 等. 三峡水库香溪河库湾特殊水温分层对水华的影响. 武汉大学学报: 工学版, 2012, 45(1): 1-9.]

[21] Reynolds CS, Bellinger EG. Patterns of abundance and dominance of the phytoplankton of Rostherne Mere, England: Evidence from an 18-year data set. Aquatic Sciences, 1992, 54(1): 10-36.

[22] Carpenter SR, Cole JJ, Hodgson JR et al. Trophic cascades, nutrients, and lake productivity: Whole-lake experiments. Ecological Monographs, 2001, 71(2): 163-186.

[23] Burns SJ. Carbon isotopic evidence for coupled sulfate reduction-methane oxidation in Amazon Fan sediments. Geochimica et Cosmochimica Acta, 1998, 62(5): 797-804.

[24] Chen Xiaoyan, Dai Huichao, Jiang Dingguo et al. Research on process of greenhouse gas emission from reservoir. Water Resources and Power, 2009, 27(5):37-39. [ 陈小燕, 戴会超, 蒋定国等. 水库温室气体排放过程中若干问题的研 究. 水电能源科学, 2009, 27(5): 37-39.]

[25] Duchemin E, Lucotte M, Canuel R et al. Production of the greenhouse gases $\mathrm{CH}_{4}$ and $\mathrm{CO}_{2}$ by hydroelectric reservoirs of the boreal region. Global Biogeochemical Cycles, 1995, 9(4) : 529-540. 